\title{
O PRIMEIRO IVO BENDER: RESSONÂNCIAS DO TEATRO DO ABSURDO NOS PRIMÓRDIOS DO PROCESSO CRIATIVO
}

\begin{abstract}
Mariana Soletti da Silva
Mestranda em Letras pela Pontifícia Universidade Católica do Rio Grande do Sul (PUCRS).

Bolsista CAPES.

solettimariana@gmail.com
\end{abstract}

\section{RESUMO}

O presente trabalho busca identificar as características cruciais do Teatro do Absurdo na primeira produção publicada do dramaturgo gaúcho Ivo Bender, nos anos 1960, chamada As cartas marcadas ou Os assassinos. Examinando conceitos a fim de fundamentar em profundidade o artigo, da teoria clássica dos gêneros às particularidades do Teatro do Absurdo, refletir-se-á acerca das similitudes entre 0 enredo e a estrutura do texto de Bender e dos atributos encontrados nas obras de Rosenfeld (1965), Staiger (1997), e Esslin (1968), da mesma maneira que outros autores e textos a prover referências imprescindíveis para o estudo.

Palavras-chave: Ivo Bender; Teatro do Absurdo; Literatura Sul-rio-grandense.

\begin{abstract}
This paper aims at identifying crucial characteristics of the Theatre of the Absurd in the first published work by the playwright Ivo Bender, in the 1960s, named As cartas marcadas or Os assassinos. Examining concepts in order to ground the article, from the classical genre theory to the particularities of the Theatre of the Absurd, this paper intends to analyze the similarities between the plot and the structure of Bender's text and the attributes found in Rosenfeld's works (1965), Staiger's (1997), and Esslin's (1968), as well as other authors' publications, which provided indispensable references for the study.
\end{abstract}

Keywords: Ivo Bender; Theatre of the Absurd; Literature from Rio Grande do Sul. 


\section{A caracterização do modo dramático e do teatro do absurdo}

A teoria clássica dos gêneros, na perspectiva de Rosenfeld (1965), observa que os termos épico, lírico e dramático descrevem estruturas literárias e determinadas características estilísticas referentes a estes gêneros. Eis, então, a análise estilística. Staiger, em Conceitos fundamentais da poética (1997), distinguiu o substantivo do adjetivo quando falamos dos gêneros. O primeiro, como uma acepção de obras relativamente pura; o segundo, com obras cujos traços estilísticos, ou tom, como a tradução preferiu empregar, relembram o gênero referido.

Staiger (1997) e Rosenfeld (1965) entendem que cada gênero pressupõe, além do modo da representação, uma série de características formais. Naturalmente, há uma aproximação entre o gênero e os traços estilísticos: uma obra que se enquadra na categoria épica possuirá características épicas. Entretanto, nenhum gênero será estritamente puro, mesmo que consigamos sintetizar aspectos importantes que determinariam se o texto é lírico, épico ou dramático. Rosenfeld (1965) comenta que a enumeração de aspectos formais de cada gênero é instrumento de sua artificialização. Por exemplo, por mais que exista uma diferença delicada entre o patético suscitado no drama e a linguagem lírica, o próprio Steiger (1997) assume que:

a linguagem do pathos confunde-se [com ela]. Tanto o êxtase lírico como igualmente o arrebatamento patético podem fazer alguém, solitário, deixar escapar palavras espontâneas, ou mesmo simples balbucios. O clímax do pathos em um drama pode vir a transformar o verso regular do diálogo em construções bem mais complicadas, que aparentemente quase não se diferenciam de estrofes líricas em algumas situações (STAIGER, 1997, p. 120).

Quanto à forma dramática em específico, é definida por Rosenfeld (1965) como aquela "em que a imitação ocorre com a ajuda de personagens que, eles mesmos, agem 
ou executam ações. Isto é, a imitação é executada por personagens em ação diante de nós", mesmo que possa manifestar outros traços (ROSENFELD, 1965, p. 16). Já Staiger (1997), de modo mais abstrato, define o dramático como a condução da ação para adiante. Duas modalidades do estilo de tensão, o patético e o problemático, unem-se para agir em conflito, assegurando a participação do público e lançando questões ao espectador. Concordam os estudiosos: o modo dramático traz obras dialogadas em que seus próprios personagens não são, em geral, apresentados por um narrador. É claro que alguns pontos cruciais do gênero também são unânimes entre eles, como a estrutura necessariamente dialógica, o encadeamento (muito discutido entre Goethe e Schiller) e a unidade de ação da produção.

Através da elevação do palco, para Staiger (1997), o pathos persuade melhor uma audiência que conserva os olhos fixos em um lugar específico, o local em que se passa a ação. De tal forma "surgiu a expressão - unidade de lugar, tempo e ação" (STAIGER, 1997, p. 134). A unidade de tempo no gênero dramático não possibilita o retorno ao passado. Não podendo retroceder, o essencial nos "quadros e passagens é que tenham significação para o todo" (STAIGER, 1997, p. 136). A definição de ir para adiante de Emil Staiger novamente dialoga com o pensamento de Anatol Rosenfeld: para ele, cada cena dramática é um elo, que encontra seu valor em um todo. Cita para isso a expressão goethiana "um avançar ininterrupto", certamente embebida por Staiger. Assim,

num drama mais ou menos puro, os fatos isolados também não são independentes. [...] Os atos facilitam a visão geral, são uma espécie de balancetes. Mesmo dentro de cada ato, há às vezes esses balanços parciais. Tanto herói como coadjuvantes resumem, por vezes, em uma frase, suas ideias ou seus pontos de vista (STAIGER, 1997, p. 135). 
Sem uma interlocução, percebemos a ausência de mediação no gênero dramático, uma vez que as ações se dão diretamente ao sujeito da leitura, que é testemunha dos acontecimentos. Logo, devem mesmo os heróis ou coadjuvantes exprimirem suas ideias, anseios e confissões. A inexistente mediação, como forma fixa, determina a autonomia dos eventos (a não ser pela voz do coro ou de um mediador). O dramaturgo não é um historiador. Ele faz da ação dramática algo sempre original, como se as ações retratadas pelo texto sempre estivessem acontecendo pela primeira vez. O seu traço é essencialmente dramático. Entretanto, deve-se lembrar que, mesmo inabalada, a teoria dos três gêneros mostra-se um tanto artificial, pois a "pureza em matéria de literatura não é necessariamente um valor positivo [...] não existe pureza de gêneros em absoluto" (ROSENFELD, 1965, p. 4). Ademais, fica claro que tal pureza não determina o valor de uma obra literária, mesmo quando ela é destinada à cena. Há a ideia que, como valor essencial do gênero dramático, absorve-se o subjetivo dentro do objetivo. Ainda Rosenfeld (1965) conta que:

tanto o narrador épico desapareceu, absorvido pelos personagens com os quais passou a identificar-se completamente pela metamorfose, comunicando-lhes toda a objetividade épica, como também se fundou o eu-lírico com os personagens, comunicando-lhes a sua intensidade e subjetividade. (ROSENFELD, 1965, p. 16)

Aprofundando-se no gênero dramático, no mesmo livro cuja primeira parte é dedicada à teoria dos gêneros, Anatol Rosenfeld discute características específicas em produções do século XIX, como a experiência do vazio. George Buchner, em 1830, já escrevia sobre a sensação de vazio em um mundo que parecia sem sentido. Outro conceito explorado por Rosenfeld é o tratamento da solidão pensando no gênero dramático. Ora, se todos são solitários, o mundo deixa de ser um todo. Cada um comunica-se diferente - o que não diz muito sobre a linguagem em si - mas como cada 
angústia o transforma "num caos absurdo em que cada qual permanece forçosamente isolado" (ROSENFELD, 1965, p. 71). Para Rosenfeld (1965), as duas sensações atacam juntas em cena. Apostos, o vazio e a solidão rompem a estrutura necessariamente dialógica do gênero dramático, levando o texto a soluções lírico-épicas. Não só criará ruídos airosos como, também, poderá revelar-se através da dissolução completa do diálogo. É:

o próprio diálogo que participa do retardamento do tempo. [...] isola os personagens, exprimindo essa paralisia da alma, já por si evidente em seres que não vivem em interação atual, mas que se escondem na 'concha das suas vivências subjetivas', ligadas ao passado relembrado ou ao futuro utópico (ROSENFELD, 1965, p. 85).

O esvaziamento do diálogo (antecipando lonesco e Beckett) é tido como "conversa mole" e "detalhes inúteis", um girar em círculo e repetições. Esse conceito é muito importante para as considerações próximas ao nosso objeto de estudo. Introduzindo noções básicas sobre o Naturalismo e o Impressionismo, Rosenfeld (1965) também discute o marasmo descrito no trabalho de Buchner, aspecto que não é surpreendente, já que icônico aos olhos do contexto sócio histórico ali presente. A visão estritamente tradicional, em que na temática do drama significa conflito, não cabia mais nas sociedades nas quais os autores conviviam.

Anton Tchekhov foi um dos que ignoraram o traço estilístico da dramaturgia rigorosa, fazendo do marasmo o próprio tema de suas peças - uma outra "coincidência" com o teatro de Ionesco e de Beckett, em que o drama consiste precisamente na falta de acontecimentos e estagnação (seja ela física ou psicológica). Então, é pela inação que a personagem carrega seus dramas, como heróis negativos. Todas essas características denotam metamorfoses nos conceitos sobre o que seria o gênero dramático na literatura. 
Esta desmistificação do gênero revelaria "que as desgraças do homem não são eternas e sim históricas, podendo por isso ser superadas" (ROSENFELD, 1965, p. 151). O homem não é fixo, mas um processo a ser entendido. Em sua forma tradicional, o homem é pressuposto como conhecido, de natureza definitiva. Assim, entendemos que quem está assistindo às cenas ou lendo o texto não só acompanha a peça como torna-se um observador, despertando a sua atividade crítica.

Alguns podem dizer que estas características inferidas por Rosenfeld (1965), sem pretensão alguma, formaram um leque de referências às peças do Teatro do Absurdo. A designação foi criada por Martin Esslin (1968). O teórico sintetiza obras cujos pontos centrais focam em aspectos inesperados da vida humana, e concentram-se em grande parte na ideia do existencialismo. A construção e o argumento lógico destas peças dão lugar ao discurso irracional e a sua conclusão final, em geral, dá lugar ao silêncio. Há uma correspondência implacável com os estudos de Rosenfeld, mesmo que Esslin aprofunde as peculiaridades de seu termo.

Por mais que o Teatro do Absurdo não possa ser considerado um movimento ou uma escola literária, para Esslin (1968), ele procura estabelecer uma nova convenção dramática. o Absurdo emprega tais características sob a perspectiva de um mundo que "perdeu sua explicação e significação central", a quem não é mais possível "continuar a aceitar formas de arte baseadas na preservação de critérios e conceitos que perderam sua validade" (ESSLIN, 1968, p. 346). Portanto, apreendemos que valores absolutos, puros, quando confrontados com a realidade da condição humana, novamente perdem sua utilidade.

As peças do Teatro do Absurdo tendem para uma desvalorização radical da linguagem, intercalando-se com os estudos de Rosenfeld (1965) em O teatro épico. No 
entanto, no Absurdo, a poesia "deve emergir das imagens concretas e objetivadas do próprio palco. O elemento da linguagem ainda desempenha papel importante nessa concepção, mas o que acontece no palco transcende, e muitas vezes [se] contradiz" (ESSLIN, 1968, p. 22). Staiger (1997) e sua elevação do palco junto ao pathos dramático juntam-se à configuração das imagens poéticas de Esslin, que:

\begin{abstract}
ao levar essa mesma busca poética à imagística concreta do palco, pode ir mais longe do que a poesia no abandono da lógica, do pensamento discursivo, e da linguagem. $O$ palco é um meio multidimensional que permite o uso simultâneo de elementos visuais, de movimento, da luz e da linguagem. É portanto, particularmente adaptado à comunicação de imagens complexas construídas pela interação de todos esses elementos. (ESSLIN, 1968, p. 349)
\end{abstract}

Mesmo com mecanismos que possibilitam uma comunicação com outras estruturas, tradições e teorias, o Teatro do Absurdo se complementa através de outros pontos, forças criativas de sua própria época e mundo. O que há de novo no Teatro do Absurdo, para o autor, é a mescla destas referências com a maneira de tornar sua plateia consciente da posição do homem no universo. Quebra-se, por exemplo, o senso de unidade: pela configuração destas imagens poéticas, o Absurdo não se preocupa com a representação de acontecimentos como quem se preocupa com a apresentação da situação básica de um indivíduo. Não à toa muitas das peças do Teatro do Absurdo têm uma estrutura circular, "terminando exatamente como começaram, enquanto outras progridem apenas por uma crescente intensificação da situação inicial" (ESSLIN, 1968, p. 361). O foco é no que se perfila a existência a existência humana.

Busca-se, agora, um elo com o Brasil. No país, traços estilísticos do Teatro do Absurdo integravam espetáculos dramáticos, o que serviria como um exercício preparatório. Os casos ressaltam, de antemão, a perspectiva social da técnica. Estes e 
outros ecos veremos a seguir, a analisar a produção cultural-teatral no Brasil principalmente nos anos 1960, quando Ivo Bender publica sua primeira peça, As cartas marcadas ou os Assassinos (1961).

\section{Breve histórico do teatro dramático no Brasil, com ênfase no século XX}

\subsection{Século XX: anos iniciais}

Décio de Almeida Prado, em O teatro brasileiro moderno (1988), retoma a evolução do teatro moderno brasileiro da década de 1930 até os anos 1980. Começa, então, com um resgate histórico - no plano internacional, na década de 1930, há a quebra da bolsa de Nova York. Aqui, a Revolução de Outubro.

Entre os anos 1930 e 1940, as sensações de crise e de insegurança, por mais que fossem suscitadas por movimentos, de certo modo, contraditórios, tiveram semelhantes impactos no teatro do Brasil. A inquietação era certa. Logo não havia descanso para as companhias. as representações aconteciam sem descanso semanal, em duas sessões, sem contar as vesperais de domingo. Geralmente, apresentavam-se à noite, oferecendo não raro uma peça diferente a cada semana. Havia muita disciplina pela diversidade de roteiros estudados e ensaiados - pressupunha-se pelo menos oito horas de atividade diária (quatro para os ensaios, à tarde; quatro para os espetáculos noturnos). No entanto, as companhias viviam em permanente improvisação.

$\mathrm{Na}$ época, levava-se muito em consideração as posições do palco e a presença do ensaiador, cujo papel era administrar a orientação geral do espetáculo. Ele deveria “traçar a mecânica cênica, dispondo os móveis e acessórios necessários à ação e fazendo os atores circularem por entre eles de modo a extrair de tal movimentação o máximo rendimento cômico ou dramático" (PRADO, 1988, p. 16). A marcação, quando fixada, era 
repetida tanto pela mesma quanto por outras companhias. Os cenários, por sua vez, eram simples, sempre reaproveitados de outras produções. Os atores "treinavam" para serem intérpretes de diferentes tipos de papéis. Assim, ficava mais mecanizado e, de certo modo, fácil para a organização das trocas de cartazes recorrente da época.

Levando em consideração as mudanças na historiografia brasileira, com a Revolução de 1930, o campo da dramaturgia evoluiu sua crítica social para além do teatro comercial, mesmo que integrado econômica e artisticamente nele. Deus lhe pague..., de Joracy Camargo (1898-1973) é um exemplo, utilizando a crise de 1929 e o nome de Karl Marx em sua trama. Um mendigo conquista uma mulher sem outra arma senão o uso da dialética, é um mendigo milionário que gosta de frases de espírito e jogos de palavras. Há uma duplicidade no texto e um ambiente paradoxal - compatível com os momentos paradoxais que viviam, entre o declínio do capitalismo e a grande Revolução de 1917. Assim, fez muito sucesso e marcou o teatro nacional. O caráter revolucionário do teatro nacional tentou ser prolongado com Amor..., de Oduvaldo Vianna (1892-1972), com o intuito sério de defender o divórcio e libertando o amor. No entanto, a sociedade brasileira ainda não estava preparada para abordar os referidos conceitos.

Peças como O Rei da Vela (1933) são exemplos de como o enredo da morte da burguesia e da rechaça ao capitalismo denotavam o caráter social e surpreendentemente libertário que o teatro brasileiro estava por tomar. Entretanto, Antônio de Alcântara Machado (1901-1935), crítico, ensaísta teatral, contista e cronista conhecido por todos, empreendeu uma vigorosa e inteligente campanha contra a inércia do nosso teatro, acusando-o de não ser, paradoxalmente, nem nacional, nem universal:

Alheio a tudo, não acompanha nem de longe o movimento acelerado da literatura dramática europeia. O que seria um bem se dentro de suas 
possibilidades, com os próprios elementos que o meio the fosse fornecendo, evoluísse independente, brasileiramente. Mas não. Ignora-se e ignora os outros. (MACHADO, 1940, p. 433)

A saída estaria na aplicação dos processos dramáticos modernos, importados da Europa, aos assuntos nacionais. A pequena abertura ensaiada logo após 1930, com textos de Oswald de Andrade, como O Homem e o Cavalo (1934), e obras cujo tom político estava inclinado para a esquerda, havia acabado. O Estado Novo fora implantado e a repressão começou. O crítico lamentou-se: "do ponto de vista literário, não do comercial, outras transformações, efetuadas lentamente, iam chegando ao fim" (PRADO, 1988, p. 35).

Nos anos 1940 e 1950, o amadorismo começa a ganhar consistência, traçando seus objetivos com clareza e profissionalismo através de grupos de teatro como o Grupo de Teatro Experimental e o Teatro do Estudante do Brasil. O ciclo de amadorismo encerra-se em 1948, com a estreia de Hamlet em português. Percebe-se, conforme diz Prado (1988), que brasileiros poderiam representar Shakespeare com profissionalismo e vanguarda ao mesmo tempo. Em 1948 também houve a criação do Teatro Brasileiro de Comédia. O TBC fez tanto sucesso que deslocou o centro do drama brasileiro do Rio de Janeiro para São Paulo. O programa era apoiar-se em textos consagrados e encenadores estrangeiros, nada muito diferente do que se fazia no Rio, porém, com mais capital. A cultura europeia ainda pesava em todos os níveis, dos técnicos até o da difusão de ideais. Sobre ela, a cultura europeia,

duas tendências dominavam o pós-guerra, parecendo configurar o teatro do futuro. A que nos vinha da França, por intermédio das peças de Sartre e Camus, incitava-nos a trabalhar em torno de conceitos e abstrações ('essência' e 'existência' tornaram-se de uma hora para outra palavras mágicas), num engajamento filosófico que prenunciava, talvez, os próximos engajamentos políticos. [...] O determinismo permanecia como doutrina, ou como hipótese, 
mas sem a primitiva rigidez. Tentava-se, em síntese, menos negar que transcender o realismo, transfigurando em poesia dramática as análises psicológicas e as explicações sociais. (PRADO, 1988, p. 49)

Por meio dessas tendências, instalou-se, no Brasil, peças de outros países cujos processos criativos estavam estritamente ligados às referidas tendências. O país "sentia a necessidade de expandir-se, escapar de quadros demasiado provincianos, ter acesso à comunidade internacional" (PRADO, 1988, p. 50). Entretanto, as temáticas abordadas foram tornando-se cada vez mais brasileiras na década seguinte.

\section{$\underline{2.1 .2 \text { Anos } 1960}$}

Consolida-se a tendência, relativamente nova, de realizar dramaturgias nacionais, retratando em cena aspectos menos conhecidos ou menos explorados no Brasil, apostando não só no autor brasileiro como em seus relatos e experiências. Bem dizendo, na vida de um brasileiro comum. Tanto o TCB quanto o Teatro de Arena ajudaram nesta consolidação; algumas de suas produções eram conjuntas às ideias de populismo e do nacionalismo. O sucesso de Eles Não Usam Black-Tie, de Gianfrancesco Guarnieri, foi um incentivo à produção local abraçando tais conceitos.

O Teatro de Arena, fundado por José Renato ao sair da Escola de Arte Dramática, em 1953, é um marco em questões sociais e estéticas. Dispensam-se cenários elaborados e, mais do que isso, reduz-se radicalmente o espaço teatral. Alguns focos de luz e algumas cadeiras são necessários à representação, retirando quaisquer empecilhos para a experiência de estar no teatro. O barateamento da experiência havia acontecido em décadas passadas, mas a ausência de galerias e camarotes fazia jus à responsabilidade política que a companhia, na época, buscava carregar. 
Outros dramas realistas de Guarnieri e Oduvaldo Vianna Filho, além de Revolução na América do Sul, de Augusto Boal, foram encenados por intermédio do Arena. Augusto Boal criou o seu texto de forma mais abstrata, com uma proposta anti-realista. Ele:

\begin{abstract}
acrescentava à dramaturgia universal um novo elemento, o questionamento crítico, não ocasional, mas exercido como método, em todos os níveis de espetáculo: crítica do autor à própria peça, desenvolvida se possível de forma interrogativa, mais como pergunta que como resposta; do ator à personagem, com a qual não devia ele se identificar a ponto de perder a objetividade; e do público, a quem caberia dizer a última palavra, elaborando a sua reflexão pessoal sobre tudo o que acabara de presenciar. (PRADO, 1988, p. 70)
\end{abstract}

Suas peças seguintes realizaram críticas sociais através de Arena Conta Zumbi (1965) e Arena conta Tiradentes (1967), em período de Ditadura Militar. Em Arena Conta Zumbi, a influência de Brecht é forte pelo distanciamento dos atores para com as personagens. Nos anos 1960, continuou-se, de qualquer forma, a existir um significativo empenho político no teatro.

\title{
3. A estreia de Ivo Bender na cena dramática brasileira
}

Ivo Bender teve uma infância pobre na colônia alemã. Filho caçula, seu irmão mais novo tinha dez anos quando nasceu. De São Leopoldo, foi para Dois Irmãos. O pai era marceneiro e precisava de emprego. Assim, perdeu amigos e continuou em torno dos irmãos mais velhos; a diferença de idade entre eles fazia de Bender uma criança solitária, segundo ele mesmo. Tinha cinco ou seis anos quando trabalhou em teatro pela primeira vez, na peça Branca de Neve e os sete anões, apresentada no palco do Jardim de Infância da Comunidade Evangélica de Dois Irmãos. Voltou a São Leopoldo e conseguiu uma bolsa e estudou durante quatro anos de graça no Sinodal. Quando passou no vestibular de Letras, na capital, conseguiu seu primeiro emprego no balcão de recepção de um hotel e 
serviu ao exército nos anos seguintes. Sentindo-se perdido, conheceu Lúcia Mello, do CAD (Curso de Arte Dramática), enquanto cursava Didática na Faculdade de Filosofia. Logo escreveu o seu primeiro texto dramático, As cartas marcadas ou Os assassinos.

Descobrimos, de antemão, que as personagens estão em um relacionamento disfuncional. a mulher, Rosário, é traída. Mas o relacionamento entre ela e Álvaro está em ruínas pois ela o trai também. Conhecem-se desde cedo, pela esquisita descrição de Álvaro. Quando deram o primeiro beijo, ela tinha oito meses e ele "um ano e alguns dias". Foi depois de um grande acidente ocorrido na casa de Álvaro. Os acontecimentos seguem causando um estranhamento, envolvendo manchas peludas atrás de canos de aquecedores que abanam os seus pelinhos quando se sentem aquecidas, por exemplo. Contando os causos da época, Rosário traz os seios decepados de Santa Ágata, amiga da avó, em uma bandeja. Uma cena à Buñuel. O casal também conversa sobre o sinal peludo que ficava atrás do aquecedor, mas que congelou no inverno e perdeu os pelos. Envergonhado, ele resolveu ir embora.

A empregada Aspérula os incomoda querendo conversar (em especial, Rosário). A história de Santiago Hera, o amante da senhora, é contada antes que ele chegue ao palco. Uma vez, ele comprou o pé esquerdo de uma múmia egípcia, mandou embuti-lo no castão de sua bengala. E um olho de cristal para usar no dia em que ficasse caolho, da exata cor de seus olhos. Mas sua compra mais célebre fora uma agulha numa loja de tratores na Sicília, por milhares de cruzeiros. Todas as suas economias foram apostadas no objeto.

O casal, ao manusear a agulha para olhá-la, acaba perdendo-a. Álvaro diz que a colocou em cima da mesa, como é descrito aos leitores, mas a agulha não está lá. Isso cria 
rusgas mais intensas entre Rosário e Álvaro. Além disso, Santiago perdeu o olho de cristal, diz que o deixou na Sicília. Não pode enxergar melhor e desvendar o mistério.

Rosário resolve a situação em instantes. Entende que a empregada roubou a agulha porque "tem mania por agulhas e por papel de pão". Então, transformou-se em um objeto qualquer (Rosário prontamente descobre que Aspérula era um açucareiro). Os três a matam, espatifando o açucareiro, e recuperam a agulha, mostrando uma excêntrica união fraternal.

Retomando as características formais explanadas no presente artigo, da teoria dos gêneros às proposições de Martin Esslin sobre o Teatro do Absurdo, a peça de Ivo Bender proporciona uma leitura que se configura como um texto dramático, mas que ao mesmo tempo está inserido na acepção do Teatro do Absurdo. A necessidade de estarem entretidos o tempo inteiro, durante um diálogo que não faz sentido, denota a falta de conversa e do próprio lazer durante os anos em que estiveram juntos. O vazio do casal, mesmo sendo dois, mostra-se latente como a solidão solitária analisada posteriormente por Rosenfeld (1965). O sentimento de vazio trabalha, juntamente ao diálogo, não ao retardamento do tempo a seu entorpecimento, mas a fazê-lo passar mais rápido através de cuidados paliativos no matrimônio.

O esvaziamento do diálogo é um girar em círculo e repetições. Na peça de Ivo Bender, ele não é dissoluto; apresenta-se de forma exacerbada e histriônica. Há um certo desespero no homem em ver-se sozinho. Por mais que a solidão em si seja individual, sem o esvaziamento do diálogo o tempo parece passar mais devagar. Notadamente, toda vez em que $\mathrm{o}$ assunto morre, as personagens ficam irritadas. Percebe-se, também, a velocidade com que mudam o assunto. É visto aqui o que diz Esslin (1968), que no Teatro 
do Absurdo pode haver uma desvalorização radical da linguagem para a subjetividade emergir das "imagens concretas e objetivadas do próprio palco" (ESSLIN, 1968, p. 22):

ÁLVARO - Sono? Sono? (Vai para Rosário) O que você quer dizer com isso? ROSÁRIO (irritada) - Por mi padre! (Levanta e sorri) Que Santiago vem nos visitar, trazendo a agulha para nos mostrar. (Uma campainha soa) Por mi sangue, é ele! (BENDER, 2005, p. 19).

O casamento continua erguido sob o moralismo e a percepção do valor do matrimônio como perene e inviolável. Para manter as aparências, o casal continua a conviver na mesma casa, esquecendo-se de seus atores sociais quando estão a sós. Álvaro parece saber do relacionamento entre Rosário e Santiago, que aparece na residência:

ROSÁRIO - Eu sabia. Aí está. Você sempre esquecendo a etiqueta. Como eu odeio o esquecimento! A etiqueta é sempre necessária. (Voltando-se) Principalmente nas roupas que se compram (BENDER, 2005, p. 21).

O caráter político, deixando às claras a emancipação do homem do teatro, não mais como forma fixa, mostra a preocupação do autor em realizar críticas sociais não só sobre o adultério, mas sobre os motivos pelos quais o adultério acontece. É de conhecimento geral que a peça trata de criticar o casamento enquanto instituição moralista, enclausuradora e de grande comoção social, "Você sabe como é a boca do povo..." (BENDER, 1965, p. 22). A crítica à burguesia, no entanto, também constrói a personagem Santiago Hera, amante de Rosário, extremamente caricata. Ele tem as coisas mais caras, viajou o mundo; nos olhos e na descrição de Rosário, Santiago Hera é um homem bem sucedido. Entretanto, sutilmente, encontramos uma opinião controversa acerca disso: "Os burgueses têm as costas largas" (BENDER, 1965, p. 26). 
Zilberman (1989) já entendia que havia tendências "variadas e controversas" na produção de Ivo Bender: a influência do existencialismo e do Teatro de Absurdo (principalmente, entre Sartre e Camus, Ionesco e Beckett). A produção de Ivo Bender recebeu da crítica comparações com o próprio teatro de Oduvaldo Vianna, Boal e Guarnieri, por denunciar os problemas econômicos e políticos do proletariado urbano brasileiro, continuando a perpetuar a onda do teatro social.

Bender, portanto, une as duas tendências - a do teatro social e a existencialista. É certo que o autor se valeu das críticas "à civilização burguesa, a perda de valores e a resultante degradação da vida", base ideológica do Teatro do Absurdo (ESSLIN, 1961, p. 192).

Especialmente no que diz a respeito da primeira década de seu trabalho, é importante lembrar que a ação de As cartas marcadas ou Os assassinos é localizada no tempo e espaço, transfigurando-se como uma peça de caráter standard ao não abolir o tempo histórico. Ela lida com problemas contemporâneos da sociedade brasileira e:

anuncia as duas linhas que percorrerá a dramaturgia de Ivo Bender: a que, valendo-se da linguagem do teatro do absurdo, critica as convenções sociais e desmascara comportamentos estereotipados; e a que dá vazão a uma representação do mundo inconsciente do indivíduo, em especial, os seus desejos e paixões, criando situações de conflito insolúvel. (ZILBERMAN, 1989, p. 17)

Bender soube incorporar bem os elementos característicos do Teatro do Absurdo, cujo significado era imenso desde seu primeiro momento. Improvável seria se ele não tivesse conhecimento dos recursos analisados. O recurso ao nonsense é outro aspecto que se alinha às peças de lonesco e de Beckett, intercaladas com diálogos randômicos e a temporalidade fora de harmonia, como diz o conceito musical da absurdidade de Esslin 
(1968). O Teatro do Absurdo "encara corajosamente o fato de não ser possível àqueles para quem o mundo perdeu sua explicação e significação central continuar a aceitar formas de arte baseadas na preservação de critérios e conceitos que perderam sua validade" (ESSLIN, 1968, p. 346). Talvez, por isso, Bender tenha composto uma linha de tempo tão disfuncional. Um exemplo é a descrição da primeira vez em que o casal Ruperstein teve uma relação sexual - o marido tinha um ano e alguns dias de idade, ao passo que a mulher, oito meses de vida. Enquanto isso, Álvaro surpreendentemente já era avô de uma menina.

A passagem trade-mark parece como crítica velada à americanização da doméstica brasileira, seguindo o American Way of Life. No diálogo, sendo ele absolutamente surreal, há uma livre associação de palavras, como se elas fizessem parte de um jogo. Sabe-se da intenção do Teatro do Absurdo de denunciar instituições moralistas, pró-establishment e burguesas. Não é de se duvidar que o autor tinha intenções maiores, mesmo que o trabalho da linguagem chame maior atenção:

ÁLVARO - Falta açúcar neste chá ou falta o trade-mark no fundo da chávena? ROSÁRIO (explicando para Álvaro e Santiago) - Deve ser o açúcar. Sempre falta o açúcar onde deve existir o trade-mark e sempre falta o trade-mark onde o açúcar deveria existir. (Para Álvaro) O trade-mark e açúcar são na verdade inconciliáveis e não compete a mim torná-los amigos!

SANTIAGO - No meu chá falta alça!

ROSÁRIO - Trade-mark, trade-mark, açúcar, trade-açúcar-mark, açúcar-marktrade, mark-trade, açúcar, mark-açúcar-trade... Ai! Mas não é possível! Não consigo conciliá-los! Ai, infeliz de mim!

SANTIAGO - No meu chá falta a alça!

ROSÁRIO - A calça? Não a calça, não a parede do quarto!

SANTIAGO (levantando-se) - A alça, a calça, a valsa!

ROSÁRIO - Não se perturbe e não perca o bom humor, meu querido. A alça está faltando, talvez. Mas a valsa vamos ouvi-la. (Põe um disco na vitrola) Eu estou sem o pires. Mas eu tenho milhares de pires guardados no porão!

ÁLVARO - O trade-mark e o açúcar, isso é o que falta. Só isso. Aspérula é uma boa criada e não posso permitir que digam que ela trouxe o chá esquecendo algo.

ROSÁRIO (levantando-se) - Pires!

SANTIAGO (levantando-se) - Alça, valsa, calça!

ÁLVARO (levantando-se) - Açúcar, trade-mark! (BENDER, 1965, p. 24-25). 
Entende-se com clareza que "no Teatro do Absurdo, toda a ação é misteriosa, nãomotivada e à primeira vista insensata" (ESSLIN, 1968, p. 357). Portanto, interliga-se com a ideia de que "a ação de uma peça do Teatro do Absurdo não pretende contar uma história, mas comunicar uma configuração das imagens poéticas" (ESSLIN, 1968, p. 349). Isso acontece em outros momentos da peça, como quando são atribuídas qualidades impossíveis a objetos como linhas de costura, máquinas de costura e tecidos. O teatro de Bender, assim como na própria Teoria do Absurdo:

\begin{abstract}
não tem por objetivo transmitir informações ou apresentar problemas ou destinos de personagens que existam fora do mundo interior do autor, como ele não propõe teses e nem debate proposições ideológicas, ele não se preocupa com a representação de acontecimentos, nem com a narração do destino ou das aventuras dos personagens, mas apenas com a apresentação da situação básica de um indivíduo. (ESSLIN, 1968, p. 349)
\end{abstract}

Os referidos objetos na passagem trade-mark podem ser uma metáfora de Ivo Bender para a costura do texto e o autor como a própria máquina, proporcionando-lhe um elo entre os personagens e a realidade. Uma realidade palpável e um universo criado através da linguagem, com aspecto de tempo-espaço excepcional. No entanto, isso jamais será posto em forma cristalina nestas produções. Não só por que não é o intuito do autor, mas porque, "no Teatro do Absurdo, o público enfrenta questões às quais falta motivação aparente, nas quais os personagens estão em fluxo constante e nas quais os acontecimentos estão nitidamente fora do campo da experiência racional" (ESSLIN, 1968, p. 361). O enigma é perene, e, por ele existir, há a crítica social. Ádams (2016) resume bem a sensação que temos ao folhearmos as páginas ou assistirmos às representações 
que não respeitam a temporalidade linear ou preceitos científicos comuns a todos seres humanos. Para ele,

a afirmativa de que a peça 'terminou antes de começar' diz muito sobre o tom de absurdidade que o texto assume. Não há nenhum tema, discussão ou 'mensagem' na peça: ela se propõe a um jogo teatral de linguagem. (ADAMS, 2016, s/p)

Concluímos que as características do Teatro do Absurdo, como acontecimentos nitidamente fora do campo da experiência racional, são identificadas em plenitude na obra de Ivo Bender. A unidade de ação, tempo e lugar, de onde decorre a verossimilhança da representação, é quebrada. O encadeamento das cenas torna-se um transgressor. A estrutura dialógica aposta na desvalorização radical da linguagem para que o intuito social da peça seja compreendido. No entanto, há elementos dramáticos que foram preservados em sua configuração padrão, como o princípio da autonomia e a pressuposição de um palco e de uma plateia. Algumas definições do drama corroboram justamente com o tecido da obra de Bender. Staiger (1997) reitera:

[...] o móvel do drama, a força que o leva adiante, é exclusivamente uma inexorável coerência com a questão final, que no fundo é a mesma inicial. Durante todo o desenrolar, o homem tem a liberdade de romper com ela ou resignar-se. (STAIGER, 1997, p. 145)

O que sustenta essa perspectiva é que muitas peças do Teatro do Absurdo têm uma natureza circular. Elas terminam exatamente como começaram, enquanto outras progridem apenas por uma crescente intensificação da situação inicial, como aponta Esslin (1968). Através dessa estrutura, por mais que exista um final impactante em As cartas marcadas ou Os Assassinos, entendemos que a normalidade pela qual o assassinato de Aspérula se dá reforça a segunda hipótese. 


\section{Referências}

ÁDAMS, Marcelo. "Ivo Bender: propostas para alguns recortes dramatúrgicos". In: Revista Cena. Porto Alegre: UFRGS, n. 19, 2016.

BENDER, Ivo. "As Cartas Marcadas ou Os Assassinos". In: Teatro Escolhido. Passo Fundo: Instituto Estadual do Livro, 2005.

BRECHT, Bertolt. Estudos Sobre Teatro. Lisboa: Portugal Editora, 1964.

ELIAS, Norbert. Os alemães. São Paulo: Zahar, 1996.

ESSLIN, Martin. Teatro do Absurdo. Rio de Janeiro: Zahar, 1968.

MACHADO, Antônio de Alcântara. Cavaquinho e Saxofone. Rio de Janeiro: José Olympio, 1940.

PRADO, Décio de Almeida. O teatro brasileiro moderno. São Paulo: Perspectiva: Editora da Universidade de São Paulo, 1988.

ROSENFELD, Anatol. "Gêneros e traços estilísticos". In: ROSENFELD, Anatol. O teatro épico. São Paulo: São Paulo Editora, 1965.

STAIGER, Emil. Conceitos fundamentais da poética. Rio de Janeiro: Tempo Brasileiro, 1997.

ZILBERMAN, Regina. "O espetáculo da vida". In: Autores Gaúchos. Passo Fundo: Instituto Estadual do Livro, 1989.

Recebido em 20 de maio de 2019.

Aceito em 09 de dezembro de 2019. 